\title{
A survey of tobacco dependence treatment services in I 2 I countries
}

\author{
Hembadoon Piné-Abata', Ann McNeill', Rachael Murray', Asaf Bitton ${ }^{3}$, Nancy Rigotti ${ }^{4,5}$ \& \\ Martin Raw'
}

UK Centre for Tobacco Control Studies, Division of Epidemiology and Public Health, University of Nottingham, Nottingham, UK,' UK Centre for Tobacco Control Studies, National Addiction Centre, Institute of Psychiatry, King's College London, London, UK, ${ }^{2}$ Division of General Medicine, Brigham and Women's Hospital, Department of Health Care Policy, Harvard Medical School, Boston, MA, USA, ${ }^{3}$ Department of Medicine, Harvard Medical School, Boston, MA, USA ${ }^{4}$ and Tobacco Research and Treatment Center, General Medicine Division, Massachusetts General Hospital, Boston, MA, USA ${ }^{5}$

\section{ABSTRACT}

Aims To report progress among Parties to the World Health Organization (WHO) Framework Convention on Tobacco Control (FCTC) in developing tobacco dependence treatment systems in accordance with FCTC Article 14 and the Article 14 guidelines recommendations. Design Cross-sectional study. Setting Electronic survey from December 2011 to August 2012. Participants One hundred and sixty-three of the 174 Parties to the FCTC at the time of our survey. Measurements The 51-item questionnaire contained 21 items specifically on treatment systems. Questions covered the availability of basic treatment infrastructure and national cessation support systems. Findings We received responses from $121(73 \%)$ of the 166 countries surveyed. Fewer than half of the countries had national treatment guidelines $(n=53,44 \%)$, a government official responsible for tobacco dependence treatment $(n=49,41 \%)$, an official national treatment strategy $(n=53,44 \%)$ or provided tobacco cessation support for health workers $(n=55$, $46 \%)$. More than half encouraged brief advice in existing health care services $(n=68,56 \%)$, while only 44 (36\%) had quitlines and only 20 (17\%) had a network of treatment support covering the whole country. Low- and middleincome countries had less tobacco dependence treatment provision than high-income countries. Conclusion Most countries, especially low- and middle-income countries, have not yet implemented the recommendations of FCTC Article 14 or the FCTC Article 14 guidelines.

Keywords FCTC, Article 14, Article 14 guidelines, survey, tobacco dependence treatment, treatment systems.

Correspondence to: Hembadoon Piné-Abata, UK Centre for Tobacco Control Studies, Division of Epidemiology and Public Health, University of Nottingham, Clinical Sciences Building, City Hospital, Nottingham NG5 1PB, UK. E-mail: mcxhp@nottingham.ac.uk

Submitted 17 December 2012; initial review completed 18 January 2013; final version accepted 25 February 2013

\section{INTRODUCTION}

Article 14 of the 2005 World Health Organization (WHO) Framework Convention on Tobacco Control (FCTC) [1] requires Parties to take effective measures to promote cessation of tobacco use and adequate treatment for tobacco dependence. In November 2010 the fourth Conference of the Parties to the FCTC adopted guidelines for the implementation of Article 14 [2]. These guidelines amount to official policy on tobacco dependence treatment for Parties to the Convention and, inter alia, outline the basic infrastructure needed to support tobacco cessation and key components of a national system to help tobacco users quit. Tobacco dependence treatment is defined by the Article 14 guidelines as: 'The provision of behavioural support or medications, or both, to tobacco users, to help them stop their tobacco use' [2].

The basic infrastructure elements to support tobacco cessation include the following [2]:

- A focal point or national coordinating mechanism

- A national cessation strategy

- National treatment guidelines

- Programmes to encourage health care workers who use tobacco to stop and support to help them do so

- National training standards

- The use, as far as possible, of existing infrastructure including but not limited to HIV/AIDS, tuberculosis and related services

- Mandatory reporting of tobacco use in all medical notes 
- Establishing a sustainable source of funding for cessation support

The key components of a national cessation support system include [2]:

- Mass communication and education programmes to encourage cessation

- Brief advice integrated into all health care systems

- Quitlines

- Access to affordable medications

- Specialized tobacco dependence treatment services The Article 14 guidelines suggest that Parties develop cessation support in a stepwise order: first establish basic infrastructure elements; then address the issue in healthcare workers; integrate brief advice into existing healthcare systems; and finally develop treatment support, including quitlines and specialist services. Finally, the guidelines state that treatment should be widely available, accessible and affordable and that cessation and treatment strategies should be monitored.

In this paper we report the results of a survey whose objective was to review the state of tobacco dependence treatment systems and national treatment guidelines in Parties to the FCTC, in order to gauge progress in implementing Article 14 and its guidelines. The survey builds on a previous survey, the results of which were published in 2009 [3,4]. We report here the treatment system results; the results on national treatment guidelines are reported in a separate paper [5].

\section{METHODS}

There were 174 Parties to the FCTC, including the European Union (EU), in addition to its member countries, at the time our survey began in December 2011. We excluded the EU, and we were unable to find contacts in 10 Parties (two high-income, three upper-middleincome, two lower-middle-income and three low-income countries), thus 163 Parties were surveyed. The United Kingdom, which is a Party, consists of four countries, England, Northern Ireland, Scotland and Wales, each with separate health care systems and treatment guidelines, so we surveyed all four individually. Our final sample therefore consisted of 163 FCTC Parties or 166 countries. Our sample of contacts-a mixture of treatment specialists, FCA members and government officials - was identified from those used in the previous survey [3,4], our own contacts and recommendations from a range of organizations. We endeavoured to identify people who were likely to be knowledgeable about tobacco cessation and treatment provision in their countries.

We e-mailed 166 people starting in December 2011, inviting them to participate in our survey by either clicking on a link to the online survey or by completing an attached Word questionnaire (offered in English, French and Spanish). We followed-up non-responders with reminder e-mails in January, February, April and May 2012.

The questionnaire contained 51 items, 21 specifically on treatment, and is available in the online version of this paper. Responses to the question on availability and licensing of medications proved difficult to interpret, partly because of its construction. Thus, we also e-mailed manufacturers of the four principal cessation medications and asked them to provide data on availability of their medications internationally. These data were used as the base to check respondents' awareness of availability and perceived affordability.

Countries were categorized by WHO region [6] and World Bank income level in August 2012, based on Gross National Income (GNI) per capita in 2011. The categories are low-income (\$1025 or less), lower-middle-income (\$1026-4035), upper-middle-income (\$4036-12 475) and high-income (\$12 476 or more) [7]. We reported the distribution of our respondents by WHO region and World Bank income category and present the main findings broken down by income category.

\section{RESULTS}

We received responses from 121 of the 166 countries surveyed, a response rate of $73 \%$. Our United Arab Emirates contact completed the survey only for Abu Dhabi. The highest and lowest response rates by region were $83 \%$ in Europe and South-East Asia, and 65\% in the Western Pacific region (Fig. 1). By World Bank income level, the highest response rate was $78 \%$ in high-income countries, and the lowest was $67 \%$ in lower-middleincome countries.

\section{Basic infrastructure elements}

According to respondents, fewer than half of countries had an official national treatment strategy (44\%), a government official responsible for tobacco dependence treatment $(41 \%)$ or national tobacco treatment guidelines (44\%). Only one-fifth of countries had a clearly identified treatment budget, and $22 \%$ did not monitor the use of treatment services (Table 1); just under half offered tobacco cessation assistance to health workers (46\%). Twenty-two per cent of countries mandated the recording of patients' tobacco use in medical notes. Just over a quarter of countries had national training standards.

\section{National cessation support system}

Just over half of countries ran anti-tobacco mass media campaigns $(54 \%)$ or encouraged the provision of brief advice in existing services (56\%) (Table 2). 


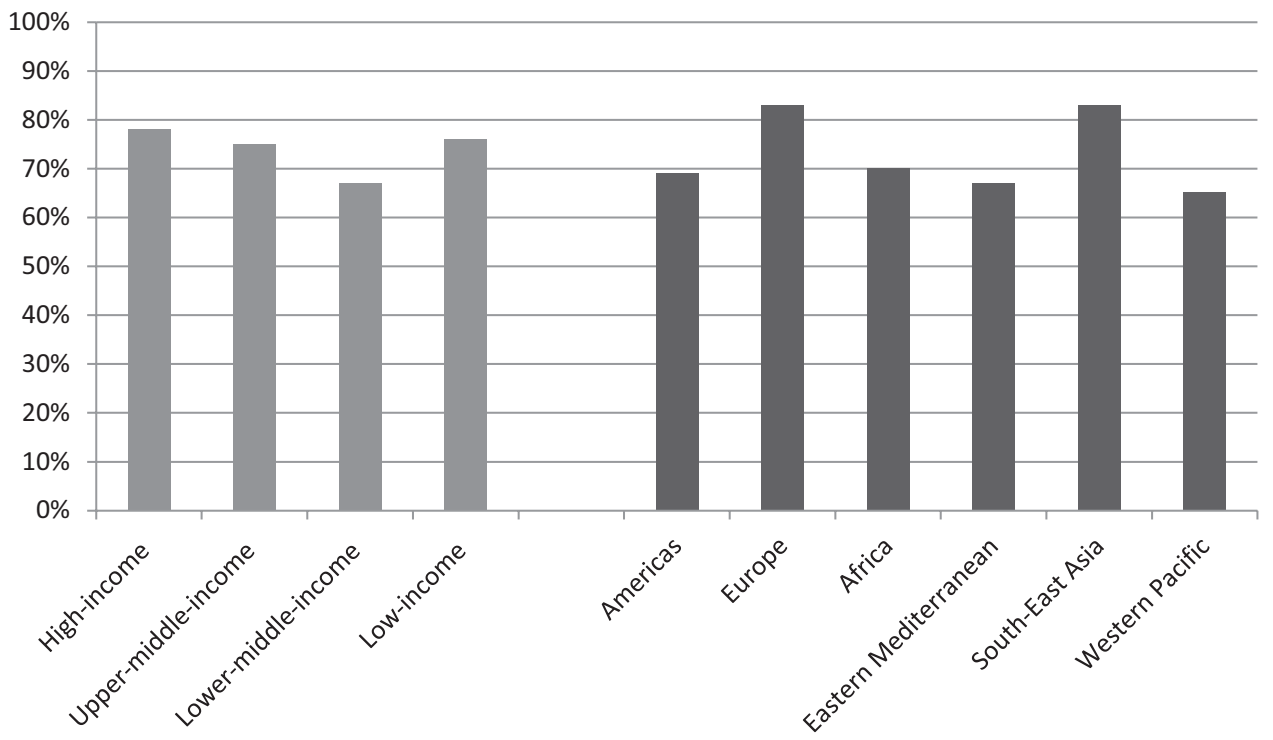

Figure I Survey response rates by region and World Bank income level of respondent countries

Table 1 Basic infrastructure elements by World Bank income level of respondent countries.

\begin{tabular}{|c|c|c|c|c|c|}
\hline \multirow[b]{2}{*}{ Question } & \multicolumn{5}{|l|}{$\%$ Yes $(n)$} \\
\hline & $\begin{array}{l}\text { All } \\
(n=121)\end{array}$ & $\begin{array}{l}\text { High } \\
(n=36)\end{array}$ & $\begin{array}{l}U M \\
(n=36)\end{array}$ & $\begin{array}{l}L M \\
(n=30)\end{array}$ & $\begin{array}{l}\text { Low } \\
(n=19)\end{array}$ \\
\hline Does your country have an official national treatment strategy? & $44(53)$ & $58(21)$ & $47(17)$ & $33(10)$ & $26(5)$ \\
\hline $\begin{array}{l}\text { Is there an officially identified person who is responsible for } \\
\text { tobacco dependence treatment? }\end{array}$ & $41(49)$ & $47(17)$ & $44(16)$ & $40(12)$ & $21(4)$ \\
\hline $\begin{array}{l}\text { Does your country have national guidelines for the treatment of } \\
\text { tobacco dependence? }\end{array}$ & $44(53)$ & $75(27)$ & $42(15)$ & $30(9)$ & $11(2)$ \\
\hline Have a clearly identified budget for treatment? & $20(24)$ & $36(13)$ & $17(6)$ & $17(5)$ & $0(0)$ \\
\hline Does your country monitor the use of treatment services? & $22(27)$ & $42(15)$ & $25(9)$ & $10(3)$ & $0(0)$ \\
\hline $\begin{array}{l}\text { Does your country offer help to health care workers to stop } \\
\text { using tobacco? }\end{array}$ & $46(55)$ & $56(20)$ & $47(17)$ & $40(12)$ & $32(6)$ \\
\hline $\begin{array}{l}\text { Does your country have mandatory recording of patients' } \\
\text { tobacco use status in medical notes? }\end{array}$ & $22(26)$ & $28(10)$ & $25(9)$ & $13(4)$ & $16(3)$ \\
\hline Does your country have national training standards? & $26(31)$ & $42(15)$ & $25(9)$ & $13(4)$ & $16(3)$ \\
\hline
\end{tabular}

$\mathrm{LM}=$ lower-middle-income; $\mathrm{UM}=$ upper-middle-income. Missing data ranged from zero to $1 \%$.

\section{Quitlines}

Respondents in 36\% of countries (44 of 121) reported having quitlines. The majority of these were free to callers and had people (rather than machines) answering calls most of the time. More than half offered multiple sessions with call-back offering support, while $86 \%$ referred callers to local specialist treatment services and $80 \%$ offered information on tobacco cessation medications. Tobacco cessation medications were offered to callers by one-fifth of quitlines.

\section{Specialist treatment facilities}

Respondents in one-third of countries reported having no specialized treatment facilities at all; just over half had treatment support in selected areas, while 17\% had a network of treatment support which covered the whole country (Table 2).

Access to help

Respondents in almost one-third (30\%) of countries indicated that tobacco users could obtain help easily in a general/family practice setting, while $17 \%$ said the same for pharmacists, $7 \%$ for dentists, $18 \%$ for hospitals and 23\% from the internet (Fig. 2).

\section{Access to medications}

Based on manufacturer data, varenicline and nicotine replacement therapy (NRT) were the most widely 
Table 2 Components of the national cessation support system by World Bank income level of respondent countries.

\begin{tabular}{|c|c|c|c|c|c|}
\hline \multirow[b]{2}{*}{ Question } & \multicolumn{5}{|l|}{$\% \operatorname{Yes}(n)$} \\
\hline & $\begin{array}{l}\text { All } \\
(n=121)\end{array}$ & $\begin{array}{l}\text { High } \\
(n=36)\end{array}$ & $\begin{array}{l}U M \\
(n=36)\end{array}$ & $\begin{array}{l}L M \\
(n=30)\end{array}$ & $\begin{array}{l}\text { Low } \\
(n=19)\end{array}$ \\
\hline $\begin{array}{l}\text { Does your country run mass media campaigns promoting } \\
\text { cessation? }\end{array}$ & $54(65)$ & $69(25)$ & $50(18)$ & $43(13)$ & $47(9)$ \\
\hline $\begin{array}{l}\text { Does your country promote/encourage brief advice in existing } \\
\text { services? }\end{array}$ & $56(68)$ & $56(20)$ & $50(18)$ & $60(18)$ & $63(12)$ \\
\hline Does your country have a telephone quitline? & $36(44)$ & $75(27)$ & $28(10)$ & $20(6)$ & $5(1)$ \\
\hline - Is it free to callers calling in? & $73(32)$ & $74(20)$ & $60(6)$ & $83(5)$ & $100(1)$ \\
\hline - Does it have people answering always or almost always? & $80(35)$ & $85(23)$ & $60(6)$ & $83(5)$ & $100(1)$ \\
\hline $\begin{array}{l}\text { - Does it offer multiple sessions with counsellors calling back } \\
\text { offering ongoing support? }\end{array}$ & $56(24)$ & $70(19)$ & $30(3)$ & $33(2)$ & $0(0)$ \\
\hline Does it refer to local specialist treatment services? & $86(38)$ & $85(23)$ & $100(10)$ & $67(4)$ & $100(1)$ \\
\hline $\begin{array}{l}\text { - Does it offer information about tobacco cessation } \\
\text { medications? }\end{array}$ & $80(35)$ & $85(23)$ & $70(7)$ & $67(4)$ & $100(1)$ \\
\hline - Does it offer tobacco cessation medications to callers? & $21(9)$ & $22(6)$ & $10(1)$ & $33(2)$ & $0(0)$ \\
\hline $\begin{array}{l}\text { Countries with nation wide specialized tobacco dependence } \\
\text { treatment facilities }\end{array}$ & $17(20)$ & $36(13)$ & $19(7)$ & $0(0)$ & $0(0)$ \\
\hline Countries with treatment facilities but only in selected areas & $51(62)$ & $50(18)$ & $56(20)$ & $57(17)$ & $37(7)$ \\
\hline Countries with no specialized treatment at all & $32(39)$ & $14(5)$ & $25(9)$ & $43(13)$ & $63(12)$ \\
\hline
\end{tabular}

LM = lower-middle-income; UM = upper-middle-income. Missing data ranged from zero to $1 \%$. The base for the quitline questions (in bullet points) for all countries was the 44 countries with quitlines and for the respective income categories was the number of countries having quitlines in each category.

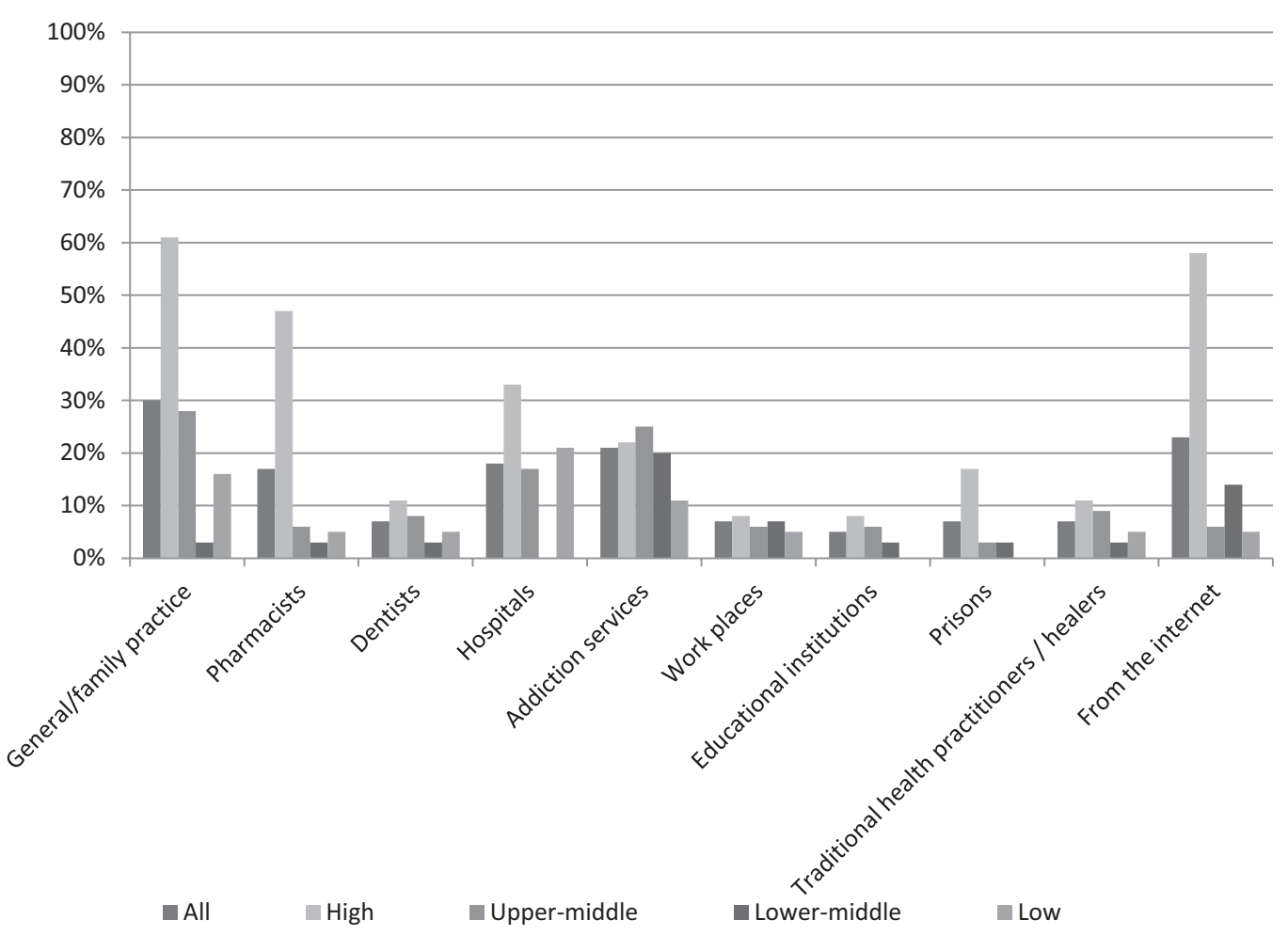

Figure 2 Can tobacco users obtain help easily to stop in the following settings? (Overall responses and responses by World Bank income level of respondent countries). The bars show the proportion answering 'Yes, easily' (Yes); the other responses were 'Not easily' and 'No' 
Table 3 Availability of medications by World Bank income level of respondent countries.

\begin{tabular}{|c|c|c|c|c|c|c|}
\hline \multirow[b]{2}{*}{ Medication } & \multicolumn{5}{|c|}{$\begin{array}{l}\text { Availability according to manufacturer } \\
\%(\mathrm{n})\end{array}$} & \multirow{2}{*}{$\begin{array}{l}\text { Respondents' awareness of medication } \\
\text { availability \% (n/base) } \\
\text { All }\end{array}$} \\
\hline & $\begin{array}{l}\text { All } \\
(n=121)\end{array}$ & $\begin{array}{l}\text { High } \\
(n=36)\end{array}$ & $\begin{array}{l}U M \\
(n=36)\end{array}$ & $\begin{array}{l}L M \\
(n=30)\end{array}$ & $\begin{array}{l}\text { Low } \\
(n=19)\end{array}$ & \\
\hline NRT & $51(62)$ & $97(35)$ & $61(22)$ & $17(5)$ & $0(0)$ & $92(57 / 62)$ \\
\hline Bupropion & $17(20)$ & $42(15)$ & $14(5)$ & $0(0)$ & $0(0)$ & $100(20 / 20)$ \\
\hline Varenicline & $52(63)$ & $83(30)$ & $58(21)$ & $33(10)$ & $11(2)$ & $86(54 / 63)$ \\
\hline Cytisine & $10(12)$ & $3(1)$ & $17(6)$ & $13(4)$ & $5(1)$ & $67(8 / 12)$ \\
\hline
\end{tabular}

$\mathrm{LM}=$ lower-middle-income; NRT = nicotine replacement therapy; UM = upper-middle-income. The bases used in the final column were the ' $n$ ' values given for the respective medications in the second column.

Table 4 Affordability of medications by World Bank income level of respondent countries.

\begin{tabular}{|c|c|c|c|c|c|}
\hline \multirow[b]{2}{*}{ Medication } & \multicolumn{5}{|c|}{$\begin{array}{l}\text { Affordability of medications known to be available } \\
\% \text { (n/base) }\end{array}$} \\
\hline & All & High & $U M$ & $L M$ & Low \\
\hline NRT & $81(46 / 57)$ & $94(32 / 34)$ & $60(12 / 20)$ & $67(2 / 3)$ & - \\
\hline Bupropion & $70(14 / 20)$ & $80(12 / 15)$ & $40(2 / 5)$ & - & - \\
\hline Varenicline & $48(26 / 54)$ & $64(18 / 28)$ & $32(6 / 19)$ & $29(2 / 7)$ & $0(0)$ \\
\hline Cytisine & $100(8 / 8)$ & $100(1 / 1)$ & $100(4 / 4)$ & $100(2 / 2)$ & $100(1 / 1)$ \\
\hline
\end{tabular}

LM = lower-middle-income; NRT = nicotine replacement therapy; UM = upper-middle-income. The bases used in the second column were the ' $n$ ' values for respondents' awareness of availability of the respective medications given in Table 3.

available medications, being available in just over half of the respondent countries (Table 3). Respondents' awareness that medications were available ranged from $67 \%$ with cytisine to $100 \%$ with bupropion.

We asked respondents if a medication was 'easily affordable to most tobacco users'. In countries whose respondents knew that the medication was available, cytisine was reported to be easily affordable in all countries, while varenicline was said to be the least easily affordable (Table 4).

\section{Relationship between treatment provision and Parties' World Bank income level}

In almost all cases, low- and middle-income countries had fewer basic infrastructure elements than highincome countries (Table 1). Fifty-eight per cent of highincome countries had an official national treatment strategy, while just over a quarter of low-income countries did. Just under half of high-income countries had an official responsible for treatment compared to only a fifth of low-income countries. Three-quarters of high-income countries had treatment guidelines as opposed to just $11 \%$ of low-income countries, and just over a third of high-income countries had a clearly identified treatment budget compared with no low-income countries.
A similar picture was observed with most components of national cessation support systems. More than twothirds of high-income countries ran mass media campaigns promoting cessation, compared with fewer than half of low-income countries, and 75\% of high-income countries provided quitlines compared with $5 \%$ of lowincome countries. Finally, 36\% of high-income countries provided specialist treatment facilities covering the whole country, whereas no low- or lower-middle-income country did, and only $14 \%$ of high-income countries provided no specialist treatment facilities at all, compared with $63 \%$ of low-income countries (Table 2). Conversely, $63 \%$ of low-income countries and $60 \%$ of lower-middleincome countries encouraged the provision of brief advice in existing services compared to $56 \%$ of highincome countries.

Access to help was rated as being easily available in general practice, pharmacies, hospitals and the internet in high-income countries, but not in any of the other World Bank income categories (Fig. 2).

The availability of NRT, bupropion and varenicline was lower in lower-income countries (Table 3). No low-income countries at all had NRT or bupropion, nor was bupropion available in any lower-middleincome countries. Cytisine was most widely available in upper-middle-income countries $(17 \%)$, followed by 
lower-middle-income countries (13\%) and low-income countries $(5 \%)$, and was least available in high-income countries (3\%). The perceived affordability of medications showed a similar pattern; it decreased steadily from highto low-income countries except for cytisine, which was considered affordable in all countries where it was available (Table 4).

\section{Relationship between treatment provision and Parties' WHO} region

No consistent pattern was observed in treatment provision by WHO region except for Africa, which was generally lower than other regions.

\section{DISCUSSION}

Only a minority of countries had in place the key infrastructure needed to offer cessation support to tobacco users. A small majority reported promoting cessation through mass media campaigns and encouraging brief advice in existing services. However, cessation help was rated as easily accessible in very few settings indeed, and even then only in high-income countries. A third of countries had no specialized treatment services at all. Availability of medications was limited, and they were frequently perceived to be unaffordable. In general, the provision of cessation support was much lower in lowerincome countries.

This study has both strengths and limitations. A key limitation of this study is that it relied upon the knowledge of our contacts and, for the most part, their responses could not be validated, although we made a considerable effort to identify contacts as knowledgeable as possible about tobacco cessation. Where responses were unclear we corresponded with respondents to ensure that the questions had not been misinterpreted and to clarify their responses. With some questions we acknowledge a degree of subjectivity in interpretation of their meaning, but there was a trade-off between attaining as large a sample as possible and keeping the questionnaire to a manageable size. With one question, on medications, we had difficulty interpreting the responses because of the way it was constructed, so we supplemented this with manufacturers' data.

In addition, the proportion of countries running mass media campaigns was higher than we expected; respondents may have included the use of unpaid media and media advocacy as well as paid mass media campaigns when responding to this question. The principal strength of this survey is that it is, to our knowledge, the most extensive, detailed survey of tobacco cessation support conducted to date, with responses from $68 \%$ of FCTC Parties.

\section{Basic cessation infrastructure}

The FCTC Article 14 guidelines (the FCTC guidelines) recommend a stepwise approach to promoting tobacco cessation and developing support, and they also recommend prioritizing approaches to providing support that are broad-reach and low-cost [2]. Our results show that most countries have not yet put into place the most basic infrastructure for promoting cessation and treatment, including an official responsible for cessation, an official national strategy and national treatment guidelines, this last a treaty obligation.

The FCTC guidelines also stress that addressing tobacco use in health care workers is a priority. Healthcare workers are health role models [8,9], tobacco use in this group undermines anti-tobacco public health messages [9], and makes health care workers less likely to encourage their patients to quit $[8,9]$. Rates of tobacco use by health professionals are as high as $40 \%$ in some countries [10,11], yet fewer than half of countries offered support to this group.

Routine recording of patients' tobacco use in medical notes is essential if health professionals are to identify and advise all tobacco users. The FCTC guidelines stress that all countries should implement this measure; fewer than a quarter have done so.

Few countries had national training standards or a system for monitoring service provision. This may be partly because of cost, and is an area where high-income countries might well be able to support lower income countries, as is encouraged by the FCTC itself.

\section{National cessation support system}

More than half of countries ran mass media campaigns promoting cessation. Such campaigns are crucial to combat the effects of tobacco industry marketing [8] as they influence attitudes to tobacco use, discourage the initiation of tobacco use, motivate quit attempts, generate demand for cessation support and inform people as to what support is available [12].

\section{Brief advice}

As noted above, the FCTC guidelines recommend integrating brief advice into the health care system as a high priority [2], and state that all countries should be doing this. The 2009 MPOWER report [13] recommends that all countries should provide brief advice, quitlines and access to low-cost medications. Brief advice is one of the most cost-effective disease prevention interventions [14], and its incorporation into health care systems such as primary care would achieve good population coverage at relatively low cost. Repeated exposure to cessation messages in health care settings has also been shown to 
increase the success of quit attempts significantly [15]. Only just over half of countries surveyed promoted brief advice in existing services; we believe this intervention should be prioritized urgently. Delivery of brief advice is likely to be linked to the recording of tobacco use in patients' notes. If tobacco use is recorded and updated regularly in patient notes this will act as a prompt to offer cessation advice on a regular basis.

Quitlines

Just over a third of countries had quitlines. Overall, the majority were free and were answered by people most of the time, but only just over half offered multiple sessions, with counsellors calling back to offer ongoing support. Although quitlines are much cheaper than face-to-face specialist treatment, these results illustrate the greater provision of cessation support in higher-income countries, and possibly suggest that for low-income countries even quitlines may be perceived to be relatively expensive [16]. Even lower-cost options such as the use of text messaging (to support tobacco users trying to quit) deserve study [17].

\section{Specialist treatment facilities}

Specialized tobacco treatment services were available widely in very few countries, and a third (63\% in lowincome countries) had no treatment services at all. The relatively high cost of establishing specialist services is almost certainly a deterrent to many countries, which is why the FCTC guidelines urge countries so strongly not to develop such services until lower-cost broader-reach interventions have been established. A number of middle-income countries [18] have established a system of specialized treatment clinics which would be extremely difficult to expand even if they could afford to do so. For a country with very limited resources to start with, specialist services are unlikely to be a cost-effective use of these limited resources.

\section{Access to help}

In the vast majority of countries, very few tobacco users could obtain help easily to stop tobacco use in any settings. Help was available most readily in general/family practice, but even in this setting tobacco users could obtain help easily in only $30 \%$ of countries. No other setting reached $25 \%$. Clearly, to expand access to cessation help quickly, countries should follow the FCTC guidelines' recommendations to focus on low-cost broad-reach interventions and on using existing infrastructure, such as primary care, to the maximum extent possible. Access to support on the internet was also low. Given its potential cost-effectiveness this approach merits more research.

\section{Access to medications}

Cessation attempts using medications are more successful than those made without medications [19-24], thus medications have an important role to play in assisting cessation. However, they were not available in all countries and in many, especially lower-income countries, were perceived as being unaffordable. Unfortunately, most countries' health care systems do not cover the cost of tobacco cessation medications and in some countries even NRT, one of the less expensive medications, is far more expensive than cigarettes $[25,26]$. In our survey, respondents in $70 \%$ or more of countries rated NRT and bupropion as easily affordable, but varenicline was judged to be affordable in fewer than half the countries in which it is available. The FCTC guidelines urge countries to look at ways of reducing the cost of medications, including by bulk-buying, for example. Cytisine was rated as being 'easily affordable to most tobacco users' in all eight countries where it was available. One was high-income, four were upper-middle-income countries, two were lowermiddle-income countries and one was low-income. The fact that a course of cytisine is reported to cost US\$15 or less $[27,28]$ suggests that more widespread licensing of cytisine could make it affordable to millions of tobacco users currently unable to afford medications.

\section{Relationship between treatment provision and Parties' World Bank income level}

Perhaps not surprisingly, almost all aspects of cessation provision were more common in higher-income countries, with the high availability of help from the internet probably reflecting better internet access in these countries. A comprehensive specialist treatment service covering the whole country, such as that established in England in 1999, can be expensive. The English services were set up with an initial budget of $\$ 83$ million [29]. We know informally that many countries are concerned by the perceived cost of cessation support, and it is because of this that the FCTC guidelines emphasize so strongly starting with affordable, broad-reach approaches, including brief advice and quitlines. Our finding that the promotion of brief advice was more common in lower- than in higher-income countries might suggest that countries are beginning to take this message on board.

\section{Relationship between treatment provision and Parties' WHO region}

The only consistent finding in treatment provision by WHO region was that provision in Africa was generally lower than in other regions, probably as a result of the predominance of low- and lower-middle-income countries in the region. 


\section{CONCLUSIONS}

To our knowledge, this is the most extensive survey of tobacco dependence treatment conducted to date, with responses from more than two-thirds of FCTC Parties. Overall, tobacco cessation support and treatment appear to be a low priority for most Parties, especially lowerincome countries. The FCTC Article 14 guidelines recommend that before establishing treatment services, countries first put into place measures proposed in other Articles of the FCTC (especially Articles 6, 8, 11, 12 and 13) that are designed to promote cessation and likely to create demand for cessation support. The Article 14 guidelines do, however, acknowledge the need for flexibility, and recommend that brief advice should be implemented in all countries as a priority. There remains much room for improvement in the extent to which low-cost broad-reach interventions can be implemented in lowand middle-income countries, with an emphasis on the stepwise approach advocated by the Article 14 guidelines.

Other areas requiring attention are establishing national coordinating mechanisms, official national strategies and help for health care workers to quit. Finally, tobacco dependence treatment is highly costeffective, and therefore should be a higher priority in higher-income countries.

Treatment provision is an integral part of wider tobacco control measures being implemented by Parties, as it indicates governments' recognition that tobacco use is addictive, and willingness to provide support to those who genuinely need it. As stated in the FCTC Article 14 guidelines, providing these services increases acceptability of and social support for other tobacco control policies [2].

\section{Declarations of interest}

Dr Rigotti has been an unpaid consultant for Pfizer and Alere Wellbeing and received royalties from UpToDate, Inc. There are no declarations of interests from the other authors.

\section{Acknowledgements}

This study was funded jointly by the University of Nottingham and the UK Centre for Tobacco Control Studies (UKCTCS), a centre for public health research excellence which is funded by the British Heart Foundation, Cancer Research UK, the Economic and Social Research Council, the Medical Research Council and the National Institute of Health Research. This funding is gratefully acknowledged. M.R.'s time on this project was funded by the Society for the Study of Addiction and the Framework Convention Alliance, to whom we are extremely grateful.
We thank Jacques Le Houezec and Vicky Baldi for translating the questionnaire into French and Spanish, respectively. Finally, we sincerely thank the country contacts who completed the survey, and the many other organizations and people who helped us identify them.

\section{References}

1. World Health Organization (WHO). WHO Framework Convention on Tobacco Control. 2003. Available at: http://www. who.int/fctc/text_download/en/index.html (accessed 17 December 2012) (Archived by WebCite ${ }^{\circledR}$ at http://www. webcitation.org/6CyciAvgl on 17 December 2012).

2. World Health Organization (WHO). FCTC/COP4(8): Guidelines for Implementation of Article 14 of the WHO Framework Convention on Tobacco Control (Demand Reduction Measures Concerning Tobacco Dependence and Cessation). 2010. Available at: http://www.who.int/fctc/protocol/guidelines/ adopted/article_14/en/index.html (accessed 17 December 2012) (Archived by WebCite ${ }^{\circledR}$ at http://www.webcitation. org/6CydD8g7r on 17 December 2012).

3. Raw M., Regan S., Rigotti N. A., McNeill A. A survey of tobacco dependence treatment guidelines in 31 countries. Addiction 2009; 104: 1243-50.

4. Raw M., Regan S., Rigotti N. A., McNeill A. A survey of tobacco dependence treatment services in 36 countries. Addiction 2009; 104: 279-87.

5. Piné-Abata H., McNeill A., Raw M., Bitton A., Rigotti N., Murray R. A survey of tobacco dependence treatment guidelines in 121 countries. Addiction 2013; 108: 14705.

6. World Health Organization (WHO). WHO Regional Offices. 2012. Available at: http://www.who.int/about/regions/en/ index.html (accessed 21 February 2013) (Archived by WebCite $^{\circledR}$ at http://www.webcitation.org/6Eb3PQSyO on 21 February 2013).

7. The World Bank. Country and Lending groups. 2012. Available at: http://data.worldbank.org/about/countryclassifications/country-and-lending-groups (accessed 21 February 2013) (Archived by WebCite $\AA$ at http://www. webcitation.org/69ZPwFWRr on 31 July 2012).

8. Glynn T., Seffrin J. R., Brawley O. W., Grey N., Ross H. The globalization of tobacco use: 21 challenges for the 21st century. CA Cancer J Clin 2010; 60: 50-61.

9. World Health Organization (WHO). Report on Tobacco Dependence and Cessation (in Relation to Article 14 of the Convention (Decision FCTC/COP2(14)). 2008. Available at: https://extranet.who.int/iris/restricted/handle/10665/ 75651 (accessed 17 December 2012) (Archived by WebCite ${ }^{\circledR}$ at http://www.webcitation.org/6CydxS4Cj on 17 December 2012).

10. Stead M., Angus K., Holme I., Tait G. Review of the Literature on Factors That Facilitate and Hinder Use of Smoking Cessation Interventions by GPs, and of Interventions to Change GP Behaviour. Stirling: University of Stirling \& The Open University Stirling; 2007.

11. World Lung Foundation and American Cancer Society. The Tobacco Atlas. 2012. Available at: http://www.tobaccoatlas. org/products/health_professionals/health_professionals_ smoke/ (Archived by WebCite ${ }^{\circledR}$ at http://www.webcitation. org/6CyhjdJ33) (accessed 17-12-2012).

12. National Cancer Institute (NCI). The Role of the Media in Promoting and Reducing Tobacco Use. 1998. NCI 
Tobacco Control Monograph Series. Available at: http:// cancercontrol.cancer.gov/brp/tcrb/monographs/19/index. html (accessed on 1 March 2013) (Archived by WebCite ${ }^{\circledR}$ at http://www.webcitation.org/6FI3dmj6q on 21 March 2013).

13. World Health Organization (WHO). WHO Report on the Global Tobacco Epidemic, 2009: Implementing Smoke-Free Environments. 2009. Available at: http://www.who.int/ tobacco/mpower/2009/en/index.html (accessed 17 December 2012) (Archived by WebCite ${ }^{\circledR}$ at http://www. webcitation.org/6CyeWf2Vt on 17 December 2012).

14. Maciosek M. V., Coffield A. B., Flottemesch T. J., Edwards N. M., Solberg L. I. Greater use of preventive services in U.S. health care could save lives at little or no cost. Health Aff 2010; 29: 1656-60.

15. Fiore M. Treating Tobacco Use and Dependence: 2008 Update: Clinical Practice Guideline. Washington, DC: US Department of Health and Human Services; 2008.

16. Abdullah A. S. M., Husten C. G. Promotion of smoking cessation in developing countries: a framework for urgent public health interventions. Thorax 2004; 59: 623-30.

17. Free C., Knight R., Robertson S., Whittaker R., Edwards P., Zhou W. et al. Smoking cessation support delivered via mobile phone text messaging (txt2stop): a single-blind, randomised trial. Lancet 2011; 378: 49-55.

18. Raw M., McNeill A., Murray R. Case studies of tobacco dependence treatment in Brazil, England, India, South Africa and Uruguay. Addiction 2010; 105: 1721-8.

19. Kasza K. A., Hyland A. J., Borland R., McNeill A. D., BansalTravers M., Fix B. V. et al. Effectiveness of stop-smoking medications: findings from the International Tobacco Control (ITC) Four Country Survey. Addiction 2012; 108: 193-202.
20. Rigotti N. A. Strategies to help a smoker who is struggling to quit. JAMA 2012; 308: 1573-80.

21. Fiore M. C., Jaén C. R., Baker T. B., Bailey W. C., Benowitz N. L., Curry S. J. Tobacco Use and Dependence Guideline Panel. Treating Tobacco Use and Dependence: 2008 Update. Clinical Practice Guideline. Rockville, MD: US Department of Health and Human Services Public Health Service; May 2008.

22. West R., McNeill A., Raw M. Smoking cessation guidelines for health professionals: an update. Thorax 2000; 55: $987-$ 99.

23. Ministry of Health. New Zealand Smoking Cessation Guidelines. 2007. Available at: http://www.health.govt.nz/ publication/new-zealand-smoking-cessation-guidelines (accessed 17 December 2012) (Archived by WebCite ${ }^{\circledR}$ at http://www.webcitation.org/6Cyg242mv on 17 December 2012).

24. Stead L. F., Perera R., Bullen C., Mant D., Hartmann-Boyce J., Cahill K. et al. Nicotine replacement therapy for smoking cessation. Cochrane Database Syst Rev 2012; CD000146. doi: 10.1002/14651858.CD000146.pub4

25. Chapman S. Tar wars over smoking cessation. BMJ 2011; 343: d5008.

26. Higashi H., Barendregt J. J. Cost-effectiveness of tobacco control policies in Vietnam: the case of personal smoking cessation support. Addiction 2012; 107: 658-70.

27. Zatonski W., Cedzynska M., Tutka P., West R. An uncontrolled trial of cytisine (Tabex) for smoking cessation. Tob Control 2006; 15: 481-4.

28. West R., Zatonski W., Cedzynska M., Lewandowska D., Pazik J., Aveyard P. et al. Placebo-controlled trial of cytisine for smoking cessation. N Engl J Med 2011; 365: 1193-200.

29. Raw M., McNeill A. Tobacco Dependence Treatment in England. Geneva: World Health Organization; 2003. 